\title{
Mitochondria and Cancer: Warburg Addressed
}

\author{
D.C. WALLACE \\ Center for Molecular and Mitochondrial Medicine and Genetics (MAMMAG), \\ Departments of Biological Chemistry, Ecology and Evolutionary Biology, and Pediatrics, \\ University of California at Irvine, Irvine, California 92697-3940
}

\begin{abstract}
Otto Warburg recognized that cancer cells generate excessive lactate in the presence of oxygen (aerobic glycolysis). It now appears that this phenomenon is the product of two factors: a return to the more glycolytic metabolism of the embryo and alterations in oxidative phosphorylation (OXPHOS) to increase mitochondrial reactive oxygen species (ROS) production. Alterations in the Ras-PI3K-Akt signal transduction pathway can result in induction of hexokinase II and its attachment to mitochondrial porin redirecting mitochondrial ATP to phosphorylate glucose and drive glycolysis. Furthermore, partial inhibition of OXPHOS by mitochondrial gene mutations (germ-line or somatic) can reduce electron flux through the electron transport chain, increasing mitochondrial ROS production. The increased ROS mutagenizes nuclear proto-oncogenes (initiation) and drives nuclear replication (promotion), resulting in cancer. Therefore, hexokinase II and mitochondrial ROS may be useful alternate targets for cancer therapeutics.
\end{abstract}

More than 70 years ago, Otto Warburg hypothesized that cancer might be caused by defects in the mitochondrion (Warburg 1931). This hypothesis was based on his observation that cancer cells actively metabolize glucose and produce excessive lactate while at the same time consuming oxygen via mitochondrial respiration. This was surprising, since most cells exhibit the "Pasteur Effect," in which glucose consumption is reduced when oxygen is available for the mitochondrial production of ATP by oxidative phosphorylation (OXPHOS) (Gatenby and Gillies 2004). Warburg called this unusual phenomenon "aerobic glycolysis" and suggested that mitochondrial defects might be central to cancer cell biology.

Since Warburg's proposal, many investigators have attempted to determine what defect in mitochondrial OXPHOS could account for tumor cell "aerobic glycolysis" (Pedersen 1978). A variety of differences between cancer mitochondria and normal cell mitochondria have been identified, including a general down-regulation of mitochondrial number and OXPHOS enzymes in cancer cells (Pedersen 1978); the up-regulation of the mRNA levels for individual mitochondrial DNA (mtDNA)-encoded genes including ND5 (LaBiche et al. 1988, 1992) and COII (Glaichenhaus et al. 1986); and the inhibition of mitochondrial ATP hydrolysis after (but not before) the addition of uncoupler (Pedersen 1978).

None of these observations adequately explained aerobic glycolysis, however, nor suggested a mechanism by which mitochondrial dysfunction could cause cancer. Hence, by the end of the 1970s, efforts to identify changes in the mitochondria associated with cancer cells had declined.

In 1988, interest in the role of the mitochondria in disease was rekindled by the discovery that mtDNA mutations can cause age-related diseases (Holt et al. 1988; Wallace et al. 1988a,b; Shoffner et al. 1990). The study of mitochondrial diseases revealed that the role of the mitochondrion in the pathophysiology of diseases was much more complex than previously imagined. It encompasses not only energy production, but also reactive oxygen species (ROS) production, as well as the regulation of programmed cell death (apoptosis) via the mitochondrial permeability transition pore (mtPTP). It was soon discovered that the MIPTP integrated information about the decline of mitochondrial energy metabolism, increased oxidative stress, and $\mathrm{Ca}^{++}$overload to determine whether the mitochondria were sufficiently impaired to justify the destruction of the cell in which they reside. This integration occurred because the mTPTP combined the pro- and anti-apoptotic members of the Bax and Bcl2 gene family; the mitochondrial outer membrane pore protein; porin (voltage-dependent ion channel or VDAC); the mitochondrial inner membrane adenine nucleotide translocator (ANT), which exchanges mitochondrial ATP for cytosolic ADP; cyclophilin D to sense calcium; and the benzodiazepine receptor. VDAC and the ANTs also form a channel for the direct export of the ATP produced in the mitochondrial matrix to the cytosol. Since there are multiple ANT isoforms, the isoform expressed is likely to affect the kinetics of ATP-ADP exchange and/or the modulation of the mtPTP to various pro- and anti-apoptotic effectors (Wallace 2005).

A major advance in understanding aerobic glycolysis came from studies on hepatoma cells relative to normal hepatic cells, specifically that transformation was associated with the increased expression of hexokinase II and the binding of hexokinase II to the mitochondria through VDAC (Bustamante and Pedersen 1977). Hexokinase II is a member of the hexokinase gene family, which consists of four isoforms: hexokinase I, II, III, and IV. Hexokinases I-III are $100-\mathrm{kD}$ proteins and are the result of a duplication of the basic 50-kD enzyme unit seen in hexokinase IV, also known as glucokinase. Even though hexokinases I-III have duplicated components, only in hexokinase II are both of the duplicated segments catalytically active. Moreover, the $K_{\mathrm{m}}$ values for glucose of hexokinases I-III are very low $\left(K_{\mathrm{m}}=0.02-0.03 \mathrm{~mm}\right)$, whereas that of hexokinase IV (glucokinase) is very high 
$\left(K_{\mathrm{m}}=5-8 \mathrm{~mm}\right)$ (Pedersen et al. 2002; Wallace 2005). Hence, expression of hexokinase II in the presence of excess ATP results in the rapid phosphorylation of glucose to glucose-6-phosphate (G6P), the commitment step for glycolysis.

In normal liver cells, glucokinase is actively expressed, whereas hexokinase II is not. However, in hepatomas, hexokinase II is strongly induced and glucokinase expression is reduced. Since hexokinase II has a strong affinity for VDAC, it can occupy the outer membrane pore through which mitochondrial ATP must escape after transport by ANT. Therefore, the hexokinase can trap mitochondrial ATP in its ATP-binding site, priming it to phosphorylate any glucose molecules that become available. The rapid processing of G6P through glycolysis generates excess pyruvate and NADH, which cannot be fully oxidized by the down-regulated cancer cell mitochondria. Consequently, the metabolites build up and are converted to lactate by lactate dehydrogenase. By this mechanism, the cancer cell generates ATP via glycolysis to buffer the effects of hypoxia associated with larger tumor masses.

Concurrent with the induction of hexokinase II, there is a change in the expression of the ANT isoforms, at least in some cell types (Torroni et al. 1990). This may optimize the flow of ATP through VDAC to hexokinase and modulate the sensitivity of the mtPTP. Moreover, since VDAC is part of the mtPTP, the binding of hexokinase II stabilizes the mtPTP and inhibits induction of apoptosis (Pedersen et al. 2002; Gatenby and Gillies 2004).

The induction of hexokinase II in cancer cells is the product of altered transcriptional control. Critical regions of the hexokinase II promoter are methylated in normal hepatocytes, keeping the gene off. However, as these regions become demethylated in hepatomas, gene expression is permitted (Goel et al. 2003). Once activated, the hexokinase II gene's expression can be regulated by glucose, hypoxia, cAMP, phorbol ester, mutated p53, insulin, and glucagon. However, it is most strongly induced by glucose, along with either hypoxia acting through hypoxia-inducible factor- $1 \alpha(\mathrm{HIF}-1 \alpha)$ or through cAMP acting by way of CREB, ATF1, and CREM. This regulation is accomplished through the hexokinase II promoter spanning nucleotides -4000 to +1 and including regulatory elements for Z-DNA, HIF/Ebox, C/EBP, AP1, Oct1, E2F, CCAAT, GRE, multiple GC regions, and a TATA box (Mathupala et al. 1997a,b, 2001; Pedersen et al. 2002; Lee and Pedersen 2003). Hence, the induction of hexokinase II in cancer cells would appear to be the product of derepression by demethylation together with transcriptional induction by glucose, hypoxia, and cAMP.

The binding of hexokinase II to mitochondrial VDAC has recently been shown to be mediated by the action of the Akt kinases, also known as protein kinase B (PKB). $A k t$ is a serine/threonine kinase and was first described as a retroviral oncogene (Bellacosa et al. 1991). It is now apparent that there are three $A k t / \mathrm{PKB}$ kinases in mammals (Akt1/PKB $\alpha, A k t 2 / \mathrm{PKB} \beta$, and Akt3/PKB $\gamma)$. The Akt kinases are activated by the binding of phosphatidylinositol-3,4,5-triphosphate and phosphatidylinositol-3,4biphosphate to the pleckstrin homology domain at the amino-terminal end of the Akt polypeptide. Phosphatidylinositol-3,4,5-triphosphate and phosphatidylinositol-3,4-biphosphate are, in turn, generated by phosphatidyinositol 3-kinase (PI3K) in response to signals from receptor and non-receptor tyrosine kinases via its regulatory subunit, $\mathrm{p} 85$. In addition, phosphatidylinositol phosphates are generated through the action of Ras, which binds directly to the catalytic p $110 \alpha$ subunit of PI3K and activates it. Thus, the $A k t$ kinases mediate the signals of a variety of oncogenes, and inhibiting Akt inhibits neoplastic transformation (Aoki et al. 1998; Testa and Bellacosa 2001; Brazil et al. 2004; Yanagihara et al. 2005). Activation of the $A k t$ kinases promotes the binding of the hexokinases to mitochondrial VDAC. This, in turn, antagonizes the pro-apoptotic action of Bax and Bak (Gottlob et al. 2001; Birnbaum 2004; Majewski et al. 2004a,b). Therefore, during neoplastic transformation, hexokinase II expression restructures the metabolism of the cancer cell mitochondria and inhibits apoptosis.

Although the biology of hexokinase II explains the upregulation of glycolysis in hypoxic cancer cells, it does not explain why glucose utilization is not down-regulated in cancer cells grown at high oxygen tension. This phenomenon still implies that mitochondrial function is compromised in the cancer cell.

Confirmation that defects in mitochondrial energy metabolism are associated with cancer have come from the discovery that certain chromosomal "oncogenes" are in fact nuclear DNA (nDNA)-encoded proteins involved in mitochondrial energy production. Mutations in the mitochondrial fumarate hydratase gene have been linked to uterine leiomyomas and renal cell carcinomas (Lehtonen et al. 2004), and mutations in three of the four subunits of succinate dehydrogenase (SDH, succinate:ubiquinone oxidoreductase, or OXPHOS complex II) have been linked to paraganglions. The pathophysiological mechanism by which defects in mitochondrial energy metabolism might contribute to cancer is suggested by the function of the various subunits in SDH. SDH (complex II) is assembled from four nDNA-encoded subunits, SDH A, B, C, and D. SDHA collects electrons from succinate in the tricarboxylic acid (TCA) cycle via a flavin adenine dinucleotide (FAD) and passes the electrons through the iron-sulfur components in SDHB to the cytochrome $b$ (cytb) and coenzyme Q (CoQ) elements in SDHD and SDHC. This reduces the ubiquinone $(\mathrm{CoQ})$ to ubisemiquinone with a first electron and then ubiquinol with a second. The reduced ubiquinol then transfers the electrons from complex II to complex III for further oxidation. Mutations in SDHB (Astuti et al. 2001; Vanharanta et al. 2004), SDHC (Baysal et al. 2000), and SDHD (Niemann and Muller 2000) all cause paraganglioma. However, mutations in SDHA cause the lethal pediatric neurodegenerative disease Leigh syndrome (Bourgeron et al. 1995), not paraganglioma. In Caenorhabditis elegans, inactivation of the cytb subunit of complex II (mev-1 mutant) markedly increases mitochondrial ROS production in association with a reduction in life span (Ishii et al. 1998; Senoo-Matsuda et al. 2001). The reduced longevity of the mev-1 mutation can be reversed by treatment with the catalytic antioxidant mimetic EUK134, a salen Mn complex (Melov et al. 2000). Thus, the C. ele- 
gans studies implicate mitochondrial ROS production in the pathophysiology of paraganglions.

It follows that mutations in the SDHB, C, and D subunits would inhibit electron flow out of complex II, creating an excess of unpaired electrons within the complex which can then be passed directly to $\mathrm{O}_{2}$ to generate $\mathrm{O}_{2}{ }^{--}$, the first of the mitochondrially generated ROS. Mutations in SDHA, in contrast, would block the entry of electrons into complex II, keeping the internal electron carriers oxidized and ROS production minimized. However, the absence of electron entry into SDHA would deprive mitochondrial OXPHOS of reducing equivalents to generate ATP, resulting in neurodegenerative disease (Wallace 2005). Thus, mitochondrial ROS production may be the missing mitochondrial link to cancer, not the gross impairment of mitochondrial energy production.

\section{MITOCHONDRIAL BIOENERGETICS}

The mitochondria generate ROS as a toxic by-product of the OXPHOS production of cellular energy. Mitochondria generate energy for two main purposes: to synthesize ATP to energize work, and to produce heat that maintains body temperature. In OXPHOS, the calories (reducing equivalents) from the carbohydrates and fats of our diet are oxidized with the oxygen that we breathe via the electron transport chain (ETC). The ETC collects electrons from NADH and $\mathrm{H}^{+}$via complex I and from succinate by complex II and transfers each pair of electrons to reduce ubiquinone to ubiquinol. Ubiquinol then transfers the electrons to complex III (the $\mathrm{bc}_{1}$ complex or ubiquinone:cytocrome $c$ oxidoreductase), which in turn donates the electrons to cytochrome $c$, and then finally passes them to complex IV (cytochrome $c$ oxidase, COX or reduced cytochrome $c$ :oxygen oxidoreductase). Here, the two electrons are passed to an atom of oxygen to generate a molecule of water (or actually, four electrons are transferred to $\mathrm{O}_{2}$ to give two $\mathrm{H}_{2} \mathrm{Os}$.) The energy that is released by the ETC is used to pump protons out across the mitochondrial inner membrane through complexes I, III, and IV. This creates an electrochemical gradient or capacitance $(\Delta \mathrm{P}=\Delta \Psi+\Delta \mathrm{pH})$ that is positive and acid on the outside and negative and alkaline on the inside. This capacitance is utilized by complex V (ATP synthase) to generate ATP via the flow of protons back into the matrix through a proton channel in the ATP synthase. The energy that is imparted to the ATP synthase via the proton flux causes the enzyme to condense bound ADP and phosphate $(\mathrm{Pi})$ to generate ATP and to then release the ATP for export to the cytosol through the ANT.

The efficiency with which calories are converted to ATP is known as the coupling efficiency. Coupling efficacy is determined by the efficiency with which the ETC pumps protons out of the mitochondrial matrix and by the efficiency with which the ATP synthase converts this proton capacitance into ATP. The more tightly coupled the mitochondria, the greater the ATP produced per calorie oxidized. The more uncoupled the mitochondria, the less ATP synthesized and the more heat generated.

Mitochondrial OXPHOS produces most of the cellular ROS. This normally occurs because complexes I and III can donate an electron directly to $\mathrm{O}_{2}$ to generate superoxide $\left(\mathrm{O}_{2}{ }^{-}\right)$. These electrons are presumably derived from the half-reduced ubisemiquinone. Superoxide is a potent oxidizing agent. However, the mitochondrial matrix contains a manganese superoxide dismutase (MnSOD) that rapidly dismutates two $\mathrm{O}_{2}{ }^{-} \mathrm{s}$ into a hydrogen peroxide $\left(\mathrm{H}_{2} \mathrm{O}_{2}\right)$. The $\mathrm{H}_{2} \mathrm{O}_{2}$ can then be converted to water by glutathione peroxidase (GPx1), but the rate of this reaction is limited by glutathione concentration. Consequently, $\mathrm{H}_{2} \mathrm{O}_{2}$ persists in the mitochondrial matrix, permitting it to diffuse out into the cytosol and the nucleus.

In the cytosol, $\mathrm{H}_{2} \mathrm{O}_{2}$ can be removed by the peroxisomal enzyme catalase. However, in the presence of reduced transition metals, $\mathrm{H}_{2} \mathrm{O}_{2}$ can acquire an additional electron, generating the most reactive oxygen compound, the hydroxyl radical $(\mathrm{OH})$. The mitochondrial generation of ROS can be substantially enhanced by partially inhibiting electron flux through the ETC either by reducing the efficiency of one of the ETC complexes or by inhibition of the ATP synthase or the ANT, thus increasing $\Delta \mathrm{P}$ to its maximum potential. Because complexes I, III, and IV cannot pump protons against a maximum $\Delta \mathrm{P}$, the ETC stalls. This results in increased electron density in the ETC carriers and increased $\mathrm{O}_{2}{ }^{-}$. Mitochondrial ROS can then damage mitochondrial enzymes, lipids, and the mtDNA.

Chronically elevated oxidative stress, reduced $\Delta \mathrm{P}$, reduced adenine nucleotides, and increased matrix $\mathrm{Ca}^{++}$ can all initiate apoptosis by activation of the mtPTP. Within the mIPTP, the ANT serves as a key regulator of permeability transition in response to adenine nucleotide and $\mathrm{Ca}^{++}$concentrations (Kokoszka et al. 2004). Hexokinase modulates the mtPTP's response to Bax and Bak by binding to VDAC (Gottlob et al. 2001; Birnbaum 2004; Majewski et al. 2004a,b). Activation of the mtPTP opens a channel through the mitochondrial inner membrane that short-circuits $\Delta \mathrm{P}$. This causes the mitochondria to swell and to release proteins stored in the mitochondrial intermembrane space into the cytosol. The released apoptotic proteins include cytochrome $c$ (cytc), procaspase-9, apoptosis initiating factor (AIF), and endonuclease G. Cytocrome $c$ binds to cytosolic Apaf-1, which then cleaves and activates procaspase-9. This initiates the digestion of cytosolic proteins by the caspase cascade. AIF and EndoG move to the nucleus and degrade the chromatin. As a consequence of these processes, a cell with the defective mitochondria is removed from the tissue by digestion from within, thus minimizing the inflammatory process (Wallace and Lott 2002).

\section{MITOCHONDRIAL DNA VARIATION IN DISEASE AND CLIMATIC ADAPTATION}

The mitochondrial genome consists of 37 mtDNA-encoded genes plus approximately 1500 nDNA-encoded chromosomal genes. The mtDNA genes include a $12 \mathrm{~S}$ and 16S rRNA, 22 tRNAs, and 13 OXPHOS polypeptide subunits (Wallace and Lott 2002). The 13 mtDNA polypeptides encompass 7 (ND1, 2, 3, 4, 4L, 5, 6) of the 46 subunits of complex I, none of the 4 subunits of complex II, 1 (cytochrome $b$, cytb) of the 11 subunits of complex III, 3 (COI, II, III) of the 13 subunits of complex IV, and 2 
(ATP6 and 8) of the 16 subunits of complex V. The mtDNA also contains an approximately 1000-nucleotide (nt) control region which encompasses the promoter for transcribing the G-rich heavy $(\mathrm{H})$ strand $\left(\mathrm{P}_{\mathrm{H}}\right)$ and the adjacent promoter to transcribe the C-rich light (L) strand $\left(\mathrm{P}_{\mathrm{L}}\right)$, the intervening mitochondrial transcription factor (mtTFA) binding sites, three conserved sequence boxes (CSB I, II, and III), the origin of H-strand replication, and the termination-associated sequence (TAS). The replication of the mtDNA H-strand has been proposed to start at $\mathrm{O}_{\mathrm{H}}$ using a cleaved transcript from $\mathrm{P}_{\mathrm{H}}$ as the primer and pausing at TAS to create the 7S DNA, thus forming the triple-stranded displacement (D)-loop. The origin of Lstrand replication is located $2 / 3$ around the mtDNA circle.

The nDNA encodes the vast majority of the mitochondrial polypeptides including the mtDNA polymerase $\gamma$, the mtRNA polymerase, the mitochondrial ribosomal proteins, the enzymes of mitochondrial metabolism, etc. The genes for these proteins are replicated and transcribed in the nucleus, the mRNAs are translated into protein on cytosolic ribosomes, and the mitochondrial proteins are selectively imported into the mitochondrion using specific import peptide sequences (Wallace and Lott 2002).

Because it is outside the nucleus, the mtDNA has unique genetics. It is inherited exclusively from the mother and is present in thousands of copies per cell which are sequestered within hundreds of mitochondria. It also has a very high mutation rate due to its constant exposure to mitochondrial ROS.

Mutations in both the nDNA and mtDNA genes of the mitochondrial genome have been linked to human degenerative diseases. Pathogenic mtDNA base substitution mutations fall into two broad categories: protein synthesis gene (tRNA and rRNA) mutations and the polypeptide gene mutations (see mitomap.org). When a new mtDNA mutation arises in a cell, this creates a mixed intracellular population of mtDNAs (heteroplasmy). As the heteroplasmic cell divides, the mutant and normal molecules segregate randomly, ultimately generating pure mutant or wild-type cell lines (homoplasmy). As the percentage of mutant mtDNAs increases, the mitochondrial energetic capacity declines, ROS production increases, and the propensity for apoptosis increases.

The accumulation of ROS damage in the thousands of mtDNAs of the cell progressively inactivates the DNA templates necessary to repair damaged mitochondria. Thus, as mtDNA mutations accumulate, due to oxidative damage, mitochondrial function erodes until the cell dies by apoptosis. As a result, the accumulation of mtDNA mutations acts as the aging clock (Wallace 2005). It is this interaction between the partial defects resulting from inherited mitochondrial defects plus the accumulation of somatic mtDNA mutations that accounts for delayed onset and progressive course of mitochondria-associated diseases. The severity of disease is the product of the extent of the inherited mutation's effect on the mitochondrial function, the percentage of mutant mtDNAs in the tissues at birth, and the additional accumulation of somatic mtDNA mutations with aging (Wallace and Lott 2002; Wallace 2005).

Over tens of thousands of years, the high mtDNA mutation rate has also generated a high degree of mtDNA single-nucleotide polymorphisms (SNPs) in indigenous populations around the world. The regional specificity of this variation is the result of two factors: (1) the sequential accumulation of mtDNA mutations along radiating female lineages as women moved into new geographical regions and (2) the selective enrichment of functional mutations that were adaptive to the new environments (Mishmar et al. 2003; Ruiz-Pesini et al. 2004; Wallace 2005). These two factors have generated region-specific branches of the mtDNA tree, frequently founded by one or more functional mutations. These regional groups of related mtDNA haplotypes are called haplogroups.

The greatest mtDNA diversity is found in Africa (Johnson et al. 1983; Cann et al. 1987; Merriwether et al. 1991; Mishmar et al. 2003), demonstrating that Africa was the origin of humans about 200,000 years before present (YBP). The most ancient African branches of the mtDNA tree are defined by the nt $3594 \mathrm{~T}$ polymorphism found in African haplogroups L0, L1, and L2. Many L0-L2 haplotypes also harbor a tRNA ${ }^{\text {Asp }}$ variant at nt $7521 \mathrm{~A}$. African haplogroup L3, which diverged from L2 and L3 by the T3594C change, subsequently gave rise to haplogroups $\mathrm{M}$ and $\mathrm{N}$, the only two lineages that left Africa to colonize all of Eurasia about 65,000 YBP. Macro-haplogroup $\mathrm{N}$ was founded by two missense mutations, one in ND3 at nt 10398A causing an A114T amino acid substitution and the other in ATP6 at nt $8701 \mathrm{~A}$ resulting in an A59T amino acid change. In Europe, macro-haplogroup $\mathrm{N}$ gave rise to the European-specific haplogroups H, I, J, $\mathrm{Uk}, \mathrm{T}, \mathrm{U}, \mathrm{V}, \mathrm{W}$, and $\mathrm{X}$. These are also founded by distinctive functional polymorphism. For example, haplogroup $U$ was found by the tRNA ${ }^{\operatorname{Leu}(\mathrm{CUN})} \mathrm{nt} 12308 \mathrm{G}$ polymorphism, and haplogroup $U$ was later subdivided by the appearance of a $16 \mathrm{~S}$ rRNA variant at nt $1811 \mathrm{G}$. Similarly, haplogroup J was founded by a reversion of the ND3 10398 back to G (T114A) and the appearance of a ND5 polymorphism at nt 13708A (A458T). Asia was colonized by derivatives of both macro-haplogroups $\mathrm{M}$ and $\mathrm{N}$, which gave rise to a plethora of Asian haplogroups, including A, B, F, etc. from N; and C, D, G, etc. from M. Sublineages of Asian haplogroup A and D also acquired the $13708 \mathrm{~A}$ variant in ND5, demonstrating the frequent convergent evolution that is seen among regional mtDNA variants.

Of all the mtDNA lineages in Central Asia, only three lineages (A, C, and D) became enriched in Northeastern Siberia by $20,000-30,000$ years ago, and these were in a position to colonize the Americas when the Bering land bridge became exposed. Hence, the two striking discontinuities in mtDNA diversity occurred as humans migrated from Africa to the Americas, one between the enormous African mtDNA diversity and the colonization of Eurasia by only $\mathrm{M}$ and $\mathrm{N}$ and the second between the extensive $\mathrm{M}$ and $\mathrm{N}$ variation in temperate Asia and the colonization of arctic Siberia by only A, C, and D. The best explanation for these geographic discontinuities in mtDNA diversity is that selection has limited the mtDNAs that could move into the higher and colder northern latitudes (Wallace et al. 1999; Mishmar et al. 2003; Ruiz-Pesini et al. 2004; Wallace 2005).

Today, these ancient adaptive mtDNA variants are in- 
fluencing individual predisposition to disease. For example, mtDNA variation that reduced the coupling efficiency and increased heat production permitted adaptation to cold but also reduced ATP production. The reduced ATP production now increases the individual's susceptibility to ATP deficiency diseases such as clinical depression and Leber's hereditary optic neuropathy (LHON) (Wallace 2005). However, these same uncoupling mutations also keep the ETC more oxidized, reducing ROS production, and thus are protective against agerelated degenerative diseases and associated with increased longevity (Wallace 2005).

\section{MITOCHONDRIAL PATHOPHYSIOLOGY OF AGING AND CANCER}

The clinical implications of mtDNA variation are not confined to degenerative diseases and aging, but also influence cancer risk, which increases with age. In fact, aging and cancer must be physiologically linked since caloric restriction in rodents both increases life span and reduces cancer risk (Harrison and Archer 1987; Masoro et al. 1992; McCarter and Palmer 1992; Masoro 1993; Sohal et al. 1994). Because calories are the fuel of the mitochondrion, this implicates the mitochondria in both aging and cancer (Fig. 1).

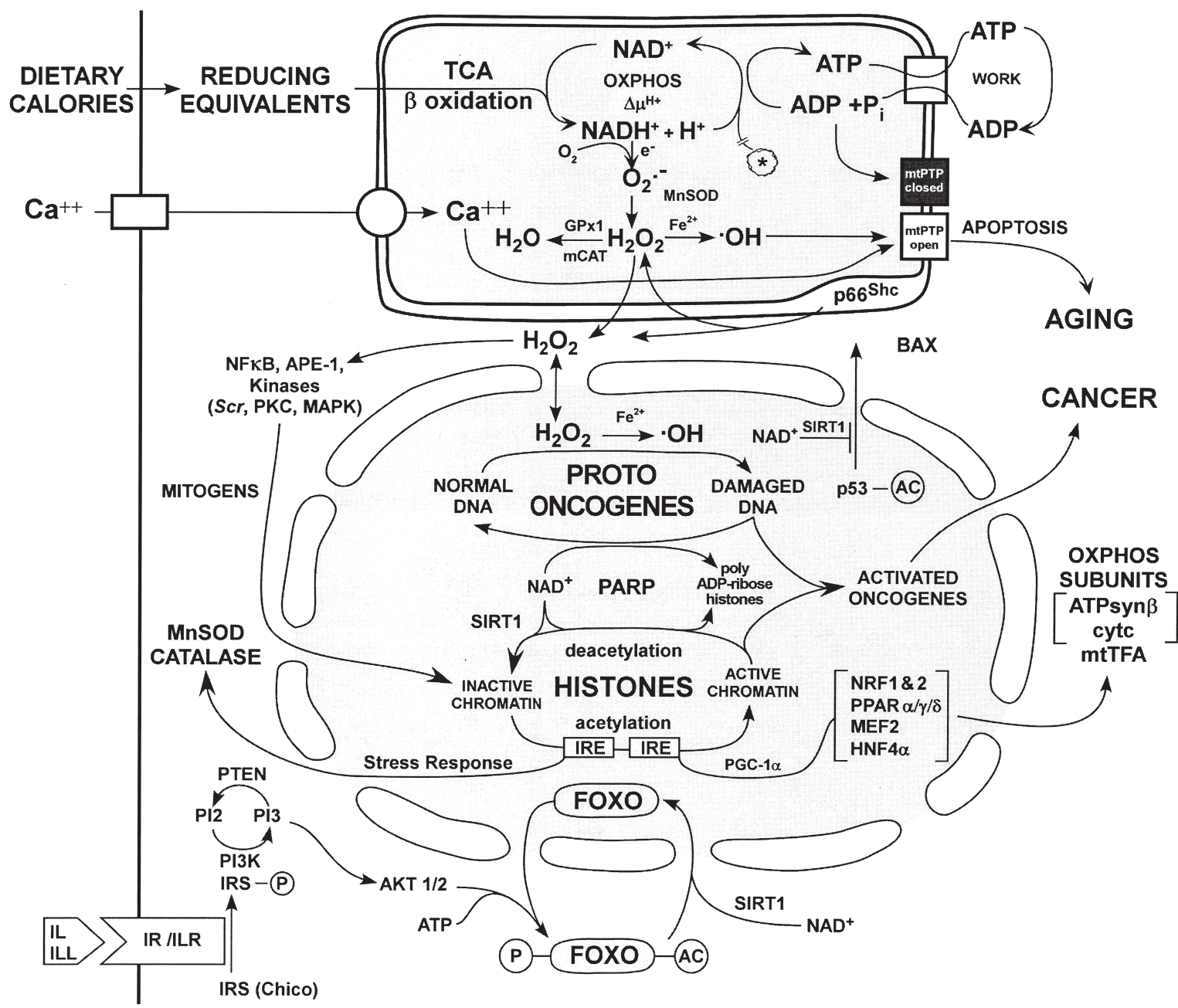

Figure 1. Model for the proposed role for mitochondrial dysfunction in an energy-utilization tissue cell in metabolic and degenerative diseases, aging, and cancer. The mitochondrial pathophysiology of these clinical entities is envisioned to result from the interplay between mitochondrial energy production, ROS generation, and the initiation of apoptosis through activation of the mtPTP. These components of energy metabolism are modulated by environmental constraints such as caloric availability and cold stress through the regulation of the FOXO and PGC- $1 \alpha$ transcription factors and the SIRT1 NAD ${ }^{+}$-dependent deacetylase. The FOXO transcription factors coordinately regulate mitochondrial energy metabolism through PGC-1 $\alpha$ as well as the antioxidant and stress response genes necessary to cope with the increased oxidative stress of oxidative metabolism. SIRT1 fine-tunes the interrelationship between energy metabolism and apoptosis through the deacetylation of PGC- $1 \alpha, \mathrm{p} 53$, and the histone proteins. Caloric overload or inhibition of OXPHOS perturbs the cellular mitochondrial energetic balance, resulting in increased ROS. The increased ROS and decreased mitochondrial energy output sensitize the mtPTP, ultimately driving the cell to apoptotic death. The increased ROS also diffuses into the nucleus as $\mathrm{H}_{2} \mathrm{O}_{2}$ where it can mutate and activate proto-oncogenes (initiation) and can interact with $\mathrm{NF}-\mathrm{KB}, \mathrm{APE}-1$, and various kinases to initiate cell division (promotion) leading to neoplastic transformation (cancer). Abbreviations: (PARP) poly ADP-ribose polymerase; (SIRT1) mammalian homolog to Sir2; (FOXO3) the most ubiquitous mammalian forkhead transcription factor; (P) a phosphorylated protein; (Ac) an acetylated protein; (IL) insulin ligand; (ILL) insulin-like ligand; (IR) insulin receptor; (ILR) insulin-like growth factor receptor; (IRE) insulin response element; (PI3K) PI3 kinase; (PI2) membrane-bound phosphatidyl-inositol diphosphate; (PI3) membrane-bound phosphatidyl-inositol triphosphate; (AKT 1/2) the AKT kinases; (ATPsyn $\beta$ ) ATP synthase $\beta$ subunit; (cytc) cytochrome $c$ (Wallace 2005). 
That the accumulation of mtDNA mutations causes aging has been established by introducing a mutator mtDNA polymerase $\gamma$ into the mouse and showing that these animals age prematurely (Trifunovic et al. 2004; Kujoth et al. 2005). That the natural mtDNA mutagen is mitochondrial ROS has been demonstrated by introducing catalase into the mouse mitochondrial matrix and showing that these animals had an extended life span and reduced mtDNA damage (Schriner et al. 2005). If ROS damage to the mtDNA modulates life span, then it might also influence cancer risk. This possibility is supported by the increased risk of paragangliomas in patients with SDH B, C, or D mutations, by the observations that mice that are heterozygous for a null mutation in the MnSOD gene have greatly increased cancer risk (Van Remmen et al. 2003), that many tumors have reduced MnSOD, that transformation of certain tumors with the MnSOD cDNA reverses the malignant phenotype, and that a cluster of three mutations in the MnSOD gene promoter is found in a number of tumors (Xu et al. 1999; McCord 2000).

If increased mitochondrial ROS production increases cancer risk, then mtDNA mutations that partially inhibit electron transport and increase ROS production might also increase cancer risk. Therefore, both somatic and germline mtDNA mutations should be associated with cancer.

Early indications that cancer cells have alterations in their mtDNAs came from the observations that human leukemia leukocytes had dimeric mtDNAs (Clayton et al. 1970), that sequences of rat liver tumors had partial deletions in the mtDNA tRNA ${ }^{\text {Tyr }}$ and tRNA ${ }^{\text {Trp }}$ genes (Taira et al. 1983), and that restriction digests of tumor mtDNAs suggested heteroplasmy (Bianchi et al. 1995). However, the first clear evidence that a mtDNA mutation in a cancer cell might be functionally significant came from the report of a renal adenocarcinoma in which $50 \%$ of the mtDNAs contained a 294-nt in-frame deletion in the mtDNA ND1 gene which generated a truncated mRNA (Horton et al. 1996). A patient with such a mtDNA mutation would manifest severe mitochondrial disease. Hence, at least some tumor somatic mtDNA mutations must be functionally important.

Subsequently, many publications have reported tumorspecific mtDNA somatic mutations that are absent in the patient's normal tissue but present as somatic mutations in the tumor tissue (Chinnery et al. 2002; Copeland et al. 2002). Analysis of ten colon cancer cell lines revealed that seven $(70 \%)$ harbored functional tumor-specific mtDNA-coding-region mutations including missense mutations in six lines and a chain termination and a frameshift mutation in the seventh. All of the mutations were homoplasmic except for the missense mutations in two of the cell lines (Alonso et al. 1997; Polyak et al. 1998; Habano et al. 1999). A survey of the mtDNAs of bladder, head and neck, and lung cancers revealed that $64 \%(9 / 14)$ of the bladder, $46 \%(6 / 13)$ of the head and neck, and $43 \%(6 / 14)$ of the lung cancers had tumor-specific mtDNA mutations. Of the 30 apparently functionally important cancer cell somatic mutations identified, 6 altered rRNA or tRNA genes, 4 affected polypeptides, and the remainder altered the control region (Fliss et al. 2000). A survey of mtDNA control region variation in gastric tumors revealed that $48 \%(15 / 31)$ of the tumors harbored tumor-specific mutations (Wu et al. 2005). Analysis of the mtDNA control region from hepatocellular carcinomas revealed that 39\% (24/61) harbored mutations in a Taiwan study (Lee et al. 2004), whereas 68\% $(13 / 19)$ had control region mutations in a Japanese study (Nomoto et al. 2002). Analysis of the mtDNAs in glioblastomas revealed predominately control region variation but also two coding region variants (Kirches et al. 2001), whereas a survey of neurofibromas from neurofibromatosis patients revealed only control region mutations (Kurtz et al. 2004). Analysis of mtDNA variation of thyroid tumors revealed control region somatic mutations in $49 \%(32 / 66)$ of tumors and coding region somatic mutations in $52 \%(34 / 66)$ of tumors in one study (Maximo et al. 2002). Another study found coding region mutants in $23 \%$ of 13 papillary thyroid carcinomas (Yeh et al. 2000). However, the thyroid tumors had a relatively low frequency of control region mutants in the hypervariable homopolymeric $\mathrm{C}$ region between $\mathrm{nt} 303$ and $\mathrm{nt}$ 315 (Tong et al. 2003). Analysis of the complete mtDNA sequence in 10 ovarian tumors revealed both control region and coding region variants in $60 \%(6 / 10)$ of cases (Liu et al. 2001). Control region and coding region mutations were also observed in $61 \%(11 / 18)$ of breast cancer samples (Parrella et al. 2001). Finally, several studies of prostate cancer tumors have revealed somatic control region mutations (Chen et al. 2002, 2003) and control region and coding region mutations (Jeronimo et al. 2001). Three heteroplasmic COI mutations have also been reported in prostate tumors that were clearly functionally important: G5949A-G16X (Stop), T6124C-M74T (interspecific conservation index $[\mathrm{CI}]=95 \%)$, C6924T-A341S $(\mathrm{CI}=100 \%)($ Petros et al. 2005). The importance of the somatic COI mutations is demonstrated by their higher average amino acid CI relative to all prostate cancer COI mutations $(\mathrm{CI}=83 \pm 25 \%)$ and to all COI variants found in the general European population ( $\mathrm{CI}=71 \pm 35 \%)$. Moreover, mitochondrial proteomic studies have revealed an increase in the ratio of nDNA to mtDNA-encoded complex IV subunits in prostate cancer patients (Herrmann et al. 2003; Krieg et al. 2004), which could be explained by mtDNA mutations in the COI-III genes.

Collation of the somatic mtDNA mutations reported from these various tumor studies reveals some remarkable associations. One of the most common mtDNA sequence variants seen in the control region of tumor cells is variation in the number of C's in the homopolymer string of C's in the nt region 303-315 (Nomoto et al. 2002; Kurtz et al. 2004; Lee et al. 2004; Wu et al. 2005; Yoneyama et al. 2005). This is also a common variant in normal tissues (Torroni et al. 1994; Trounce et al. 1995). Moreover, the majority of the somatic control region mutations observed in cancer tissues, such as nts 73, 16189, and 16519 , have also been reported to be polymorphisms in population studies (Yoneyama et al. 2005). The 16189 $\mathrm{T}$ to $\mathrm{C}$ variant is particularly intriguing, since it converts at $\mathrm{T}$ that disrupts a string of C's $\left\{\mathrm{CCCCCT}^{16189} \mathrm{CCCC}\right\}$ to a $\mathrm{C}\{\mathrm{CCCCCCCCCC}\}$, thus encouraging slip mispairing and the destabilization of this region on the mtDNA. This same variant has been associated with increased risk 
for Type 2 diabetes mellitus (Poulton 1998; Poulton et al. 1998), dilated cardiomyopathy (Khogali et al. 2001), and endometrial cancer (Liu et al. 2003). Similarly, in one Taiwanese case of gastric cancer, the patient's tumor was found to be heteroplasmic for a 270-nt insertion between nt 309 and nt 568. This was associated with instability in the number of C's in a homopolymeric string starting at nt 568 (Wu et al. 2005). Interestingly, this same duplication was found to be a characteristic of European haplogroup I (Torroni et al. 1994) and has been implicated in predisposition to mtDNA rearrangements (Brockington et al. 1993). The presence of similar mtDNA control region mutations in tumors and populations raises the possibility that the mitochondria may be exposed to similar selective forces in both populations and tissues.

The concept of selection resulting in convergent mtDNA mutations in human populations and tumors has been further supported by comparing the functional mtDNA variants (rRNA plus tRNA and polypeptide) observed in cancer cells with those in human populations. Focusing on the tumor-specific mtDNA tRNA and rRNA gene mutations, a total of 19 mutations have been reported to be tumor-specific (present in tumors but not in normal tissue) in ovarian (Liu et al. 2001), bladder, head and neck (Fliss et al. 2000), colon (Polyak et al. 1998), thyroid (Yeh et al. 2000), and prostate (Jeronimo et al. 2001) cancer. Most of these somatic mutations are either homoplasmic or approaching homoplasmic in the tumors. Comparison of these "tumor-specific" tRNA and rRNA mutations with our global human mtDNA database of $2453 \mathrm{mtDNA}$ coding region sequences (Brandon et al. 2006) revealed that $53 \%(10 / 19)$ of the somatic tumor mutations have been previously described as population variants (Mishmar et al. 2003; Ruiz-Pesini et al. 2004). For example, in one prostate tumor, a somatic tRNA ${ }^{\mathrm{Leu}(\mathrm{CUN})}$ mutation converted nt A12308G (Jeronimo et al. 2001). The $12308 \mathrm{G}$ allele defines the European mtDNA haplogroup $\mathrm{U}$ and is found in 262 of the 2453 mtDNAs in our collection. Similarly, a 16S rRNA variant found in the head and neck tumors converted nt A1811G (Fliss et al. 2000). The $16 \mathrm{~S}$ rRNA $1811 \mathrm{G}$ allele subdivides haplogroup $\mathrm{U}$ and is present in 163/2453 mtDNAs. Finally, in a thyroid tumor, a tRNA ${ }^{\text {Asp }}$ mutation changes nt G7521A (Yeh et al. 2000). The 7521A allele is prevalent in African haplogroups L0-L2 and is present in 121/2453 mtDNAs. In contrast, the $7521 \mathrm{G}$ allele appears in African haplogroup L3 and is the primary allele in macro-haplogroups M and N (Brandon et al. 2006).

Similarly, multiple tumor mtDNA polypeptide gene variants have also been observed in population samples. Forty-seven functionally relevant somatic mtDNA polypeptide mutations have been reported for ovarian (Liu et al. 2001), glioblastoma (Kirches et al. 2001), bladder, head and neck (Fliss et al. 2000), colon (Polyak et al. 1998), thyroid (Yeh et al. 2000; Maximo et al. 2002), breast (Parrella et al. 2001), and prostate (Jeronimo et al. 2001; Chen et al. 2003) tumors. Five of these are rearrangements and can be excluded from the comparison. The remaining 42 are missense mutations of which 22 (52\%) are also population polymorphisms (Brandon et al. 2006).

Some of the cancer somatic mutations are major mtDNA population markers. For example, one thyroid tumor was reported to have a somatic mutation that changed A10398G (Yeh et al. 2000). Variation at this nucleotide delineates several of the most significant mtDNA lineages. The $10398 \mathrm{G}$ allele which determines that the ND3 codon 114 is an alanine (A) is the primary allele for African haplogroups L0-L3 and Asian macro-haplogroup M. However, at the root of macro-haplogroup $\mathrm{N}$, this base changes to 10398A and the ND3 114 amino acid becomes threonine (T). Subsequently, in three sublineages of macro-haplogroup $\mathrm{N}$, specifically European haplogroups $\mathrm{J}$ and $\mathrm{Uk}$ as well as a sublineage of Asian haplogroup B, the base returns to $10398 \mathrm{G}$ and the ND3 amino acid back to A. Thus, in this thyroid tumor patient, the European A allele of the normal tissue is changed to the African $\mathrm{G}$ allele in the tumor tissue. The $10398 \mathrm{G}$ allele found in the tumor is present in 1072/2453 mtDNAs. Similarly, two independent thyroid tumor patients were reported to have a somatic A8701G mutation (Maximo et al. 2002). The $8701 \mathrm{G}$ allele (ATP6 codon 59A) is prevalent in Africa and in macro-haplogroup M mtDNAs. However, at the base of macro-haplogroup N, the base becomes 8701A and the ATP6 amino acid becomes 59T. Thus, in these thyroid tumor patients, the European $8701 \mathrm{~A}$ allele in normal tissue is converted to the African $8701 \mathrm{G}$ allele in cancerous tissue. The $8701 \mathrm{G}$ allele is found in 762/2453 mtDNAs. Finally, a breast cancer tumor was reported to have acquired a G13708A somatic mutation (Parrella et al. 2001). This variant has arisen several times in human radiation. The founding allele $13708 \mathrm{G}$ (ND5 codon 458A) is found in African L0-L3, Asian M, and at the base of Eurasian $\mathrm{N}$ mtDNAs. However, at the base of European haplogroup $\mathrm{J}$ and in important sublineages of the European X and Asian B haplogroups, the 13708 base changes to A and the associated ND5 amino acid 458 is changed to a T. The $13708 \mathrm{~A}$ found in the tumor is seen in 209/2453 mtDNAs (Brandon et al. 2006).

One possibility is that these "tumor-specific mtDNA variants" are simply sequencing errors in the patient's tumor or normal mtDNA sample. However, this seems unlikely, since the control region mutations found in tumors also correlate with population variants, different high-frequency population variants have been reported in five independent studies, and the gel for the somatic nt 13708 variant in a breast cancer patient is published and is very convincing. In this breast cancer patient, the nucleotide variant is completely absent in both the peripheral blood sample and the adjacent normal tissue of the patient, but is strongly present in both the tumor tissue and a metastatic node of the same individual (Parrella et al. 2001; Brandon et al. 2006). Hence, we must conclude that at least some tumor mutations are the same as population polymorphisms. As a result, this implies that similar selective forces must be acting on the mtDNAs in both populations and transformed cells. This seems plausible, since in both circumstances the availability of substrates (calories and oxygen) for energy production, the effects of thermal stress, and the function and consequences of ROS production and apoptosis would be equally applicable.

The correlation of population-specific variants and tumor somatic mutations also suggests that individuals who inherit certain population variants might be more prone to 
cancer. This concept has been supported in two instances. The control region variant at $16189 \mathrm{~T}$ to $\mathrm{C}$, which destabilizes the mtDNA control region, is associated with increased risk for endometrial cancer (Liu et al. 2003), and the 10398 allele has been found to increase the risk for invasive breast cancer in both premenopausal and postmenopausal African-American women over women with the $10398 \mathrm{G}$ allele. However, the $10398 \mathrm{G}$ allele did not increase breast cancer risk for Caucasian women (Canter et al. 2005). Interestingly, the $10398 \mathrm{G}$ allele is found in subSaharan African mtDNAs and in European haplogroup J mtDNAs (Brandon et al. 2006), and an A to G somatic mutation at nt 10398 was found in a patient with papillary thyroid carcinoma (Yeh et al. 2000).

To further investigate the role of germ-line mtDNA variants in cancer risk, we have surveyed the nature and frequency of mtDNA COI gene variants in EuropeanAmerican prostate cancer specimens. We chose to focus on the COI gene because preliminary studies had revealed that COI was hypervariable in prostate cancer samples (Petros et al. 2005), proteomic studies had reported an increase in the ratio of $\mathrm{nDNA} / \mathrm{mtDNA}$-encoded complex IV polypeptides in prostate cancer (Herrmann et al. 2003; Krieg et al. 2004), and haplogroup-specific polymorphisms in COI are rare in Europeans, minimizing background effects (Mishmar et al. 2003; Ruiz-Pesini et al. 2004). The mtDNA COI genes from 260 prostate cancer specimens from North American patients of predominantly Eurasian descent were sequenced along with blood samples from 54 prostate cancer negative men over age 50 whose PSA was $<1$ and in which a prostate needle biopsy was free of cancer cells. This analysis revealed that in European-Americans, COI mutations were found in $11 \%$ of the prostate cancer specimens and $0 \%$ of the prostate cancer negative controls. Furthermore, four prostate cancer COI mutations were found in multiple independent patient tumors, often on different mtDNA backgrounds. The first mutation, nt T6253C, was found in three independent prostate cancer specimens, all haplogroup H. This base substitution caused a M117T amino acid substitution (CI of $69 \%$ ). The second mutation, nt C6340T, was found in six patients on haplogroups $\mathrm{J}, \mathrm{T}$, L1, and N and caused an A120T (CI of 97\%). The third mutation, nt G6261A, was found in two cases with haplogroups of $\mathrm{H}$ and $\mathrm{N}$, converted amino acid T146I (CI of $79 \%$ ). The final mutation, nt A6663G, was found in five cases on haplogroups $\mathrm{O}$ and L2 and changed amino acid I125V (CI of 95\%). Thus, these data prove that germ-line mtDNA COI mutations can cause prostate cancer and thus are oncogenes (Petros et al. 2005).

Surprisingly, a survey of 898 random European mtDNA sequences revealed that $5.5 \%$ of the general population also harbored COI variants. If COI mutations cause prostate cancer, why would they persist in the population? The answer is that only men develop prostate cancer, whereas only women transmit the mtDNA. Hence, the mutant mtDNAs are insulated against selection.

To demonstrate that mtDNA mutations can indeed be oncogenic, we substituted the mtDNAs of a prostate cancer cell line, PC-3, with the mtDNAs from a mitochondrial disease patient who was heteroplasmic for a known pathogenic mtDNA mutation, T8993G (Holt et al. 1990). By isolating cytoplasmic hybrid (cybrid) cell lines that were homoplasmic for the mutant or wild-type mtDNAs, these cell lines could be used to transfer the two mtDNA genotypes into the presence of a prostate cancer cell nucleus, and the effects on tumorigenicity of the mutant and wild-type bases can be assessed. An ATP6 mutant was chosen because we had observed that the prostate tumor which harbored the somatic COI G16X chain termination mutation also harbored a homoplasmic germ-line ATP6 C8932T (P136G) variant with a CI of 64\%. Hence, ATP6 mutations may also contribute to the prostate cancer risk of the patient.

The T8993G mutation causes a L156R amino acid change approximately 20 amino acids away from the C8932T mutation. Biochemical analysis of the wild-type T8993T versus the mutant T8993G mtDNA in cybrid lines has revealed that the homoplasmic mutation resulted in an approximately $70 \%$ reduction in ATP synthase (complex V) activity (Trounce et al. 1994). An independent study established that the T8993G mutation also increased mitochondrial ROS production (Mattiazzi et al. 2004). To transfer the T8993T and T8993G mtDNAs into the PC-3 cell line, we treated the PC-3 cells with the mitochondrial poison, rhodamine $6 \mathrm{G}$ (R6G), to destroy their resident mitochondria and mtDNAs. The homoplasmic T8993T or the homoplasmic T8993G cybrids were then enucleated, and cytoplasts were fused to the R6G-treated PC-3 cells (Trounce et al. 1996). The resulting PC-3 (mtDNA T8993T) and PC-3 (mtDNA T8993G) cybrids were then injected into nude mice. Analysis of multiple cybrid clones revealed that the PC-3 cells with the wildtype (T8993T) mtDNA barely grew in the nude mice, whereas the PC-3 cybrids with the mutant (T8993G) mtDNA grew rapidly and required that the animals be euthanized due to excessive tumor size. Therefore, we can conclude that mtDNA mutations can contribute substantially to tumorigenesis and that a single deleterious base change in the mtDNA can enhance malignant growth (Petros et al. 2005).

To determine whether the increased tumorigenicity of the mutant (T8993G) mtDNA cybrids was due to increased ROS production, we stained the injected cell nodules from the nude mice for ROS production with dihydroethidium. This revealed that the mutant $(\mathrm{T} 8993 \mathrm{G})$ cell line tumors were producing excessive ROS whereas the wild-type T8993T mtDNA nodules were producing very little ROS (Petros et al. 2005). Thus, mitochondrial ROS production is again implicated in the transformation of cells.

\section{A MITOCHONDRIAL PATHOPHYSIOLOGY OF CANCER}

These observations suggest that the mitochondrial paradigm of aging and age-related diseases (Fig. 1) (Wallace 1992, 2005) can provide a coherent picture of the role of the mitochondria in cancer. Mitochondrial OXPHOS chronically generates ROS as a toxic by-product. The relative level of ROS production is determined by the coupling efficiency of the individual's mitochondria, which is a consequence of his/her mtDNA and nDNA 
genotype, the dietary caloric load, and environmental agents that might inhibit mitochondrial energy production. Thus, individuals with cold-adapted, partially uncoupled mitochondria would produce less ROS in the presence of a relatively high caloric load than would individuals with more tightly coupled mitochondria adapted to a warmer climate.

The chronic OXPHOS generation of $\mathrm{O}_{2}{ }^{--}$and $\mathrm{OH}$ progressively damages mitochondrial OXPHOS enzymes, membranes, and the mtDNA. The mtDNA template is used to repair the protein damage, but this fails when the mtDNA information becomes corrupted. Excess mitochondrial $\mathrm{H}_{2} \mathrm{O}_{2}$ diffuses out of the mitochondrion and into the cytosol and the nucleus, where it interacts with mitogenic signal transduction pathways including NFкB, APE-1, Fos, Jun, and tyrosine kinases (Src kinase, protein kinase $\mathrm{C}, \mathrm{MAPK}$, and receptor tyrosine kinases) and the dual functional apurinic/apyrimidinic endonuclease 1 (APE-1) which redox regulates Fos, Jun, NF- $\kappa B$, PAX, HIF-1 $\alpha$, and p53 (Evans et al. 2000; Kelley and Parsons 2001), thus driving the cell into mitosis.

Damage to the nDNA also activates the nuclear DNA repair system including poly ADP-ribose polymerase (PARP). PARP converts the nuclear $\mathrm{NAD}^{+}$into poly ADP-ribose linked to nuclear proteins, thus depleting nuclear $\mathrm{NAD}^{+}$. The nuclear $\mathrm{NAD}^{+}$level is further depleted by its reduction to NADH as a consequence of the inhibition of the mitochondrial ETC. Depletion of nuclear $\mathrm{NAD}^{+}$deprives the protein deacetylase, SIRT2, of its obligatory substrate $\mathrm{NAD}^{+}$, thus inhibiting deacetylation of histones, the forkhead transcription factors (FOXOs), and p53. The lack of deacetylation of the histones biases them toward the acetylated state, which opens the chromatin, permitting transcription of previously silenced developmental and replication genes, thus permitting expression of the activated oncogenes (Fig. 1).

The activation of the tryrosine kinases and/or Ras activates the PI3 kinase, which in turn activates the $A k t / \mathrm{PKB}$ kinases. The oncogene-induced replication of the pretransformed cells in solid, unvascularized tissue results in hypoxia and induction of hexokinase II transcription, and the $A k t / P K B$ kinases promote the binding of the hexokinase II to mitochondrial VDAC, thus coupling mitochondrial ATP production to driving glycolysis. The activated Akt/PKB kinases then phosphorylate the FOXO transcription factors. The phosphorylation of the FOXOs and the lack of SIRT2 deacetylation remove the FOXOs from the nucleus.

When unphosphorylated and unacetylated, the FOXO transcription factors enter the nucleus and bind to the insulin response elements (IREs) in gene promoters. Important IRE-containing genes include antioxidant genes such as the mitochondrial MnSOD gene and the master mitochondrial biogenesis gene regulator, the Peroxisome-Proliferation-Activated Receptor $\gamma$ (PPAR $\gamma)$-Coactivator $1 \alpha(\mathrm{PGC}-1 \alpha)$. Expression of PGC- $1 \alpha$, in turn, activates transcription factors such as NRF-1 and 2 and PPARP $\gamma$ to up-regulate mitochondrial biogenesis.

Hence, when the FOXOs are rendered inactive by phosphorylation and acetylation, mitochondrial OXPHOS and mitochondrial antioxidant defenses are down- regulated, further increasing mitochondrial ROS production and mtDNA mutagenesis (Fig. 1) (Wallace 2005). This down-regulation of OXPHOS via the $A k t / \mathrm{PKB}$ and FOXO pathway probably explains the commonly observed reduction of mitochondrial number and OXPHOS enzymes in cancer cells (Pedersen 1978).

The oncogene activation of the $A k t / \mathrm{PKB}$ kinases also results in the binding of the hexokinase II to the mitochondrial VDAC. This harnesses mitochondrial ATP production to drive glycolysis generating excessive pyruvate and NADH. At the same time, the FOXO-mediated down-regulation of mitochondrial OXPHOS and the inheritance or acquisition of inhibiting mtDNA variants increases mitochondrial ROS production which acts as a mitogen. Moreover, suppression of OXPHOS renders the mitochondria incapable of oxidizing all of the pyruvate and NADH. Consequently, the excess pyruvate and NADH are combined by lactate dehydrogenase to generate lactate in the presence of oxygen "aerobic glycolysis."

The inactivation of p53 further activates the transcription of hexokinase II and inhibits Bax transcription, both inhibiting apoptosis. Moreover, functional p53 is imported into the mitochondrion, where it interacts with the mtDNA polymerase $\gamma$ and enhances its mtDNA replication function. Hence, the loss of p53 significantly increases mtDNA vulnerability to damage and mtDNA mutation rate (Achanta et al. 2005).

The cumulative ROS damage and loss of p53 fidelity lead to increased mtDNA somatic mutations. Those that partially impede the ETC accentuate ROS production without completely blocking ATP production. The increased ROS drives cellular division, whereas the continued generation of ATP continues to support hexokinaseII-initiated glycolysis.

Increased ROS production can be achieved in multiple ways. Certain mtDNA mutations can impede, but not stop, electron transport. Such mtDNA mutations either can arise de novo in the cancer cells as somatic mutations or can be inherited through the female germ line either as new deleterious germ-line mutations or as ancient adaptive polymorphisms. For individuals harboring mtDNA variants that partially inhibit the ETC, excessive caloric load will increase ROS production, thus increasing cancer risk.

The increased ROS production is advantageous to the cancer cell in driving replication, but it also chronically damages the mitochondria and the mtPTP. The ROS-oxidized mtPTP is particularly prone to activation by decreases in mitochondrial inner membrane potential $(\Delta \mathrm{P})$. Activation of the mtPTP, in turn, results in increased mitochondrial ROS production (Cai et al. 2000), possibly due in part to the redirection of electrons borne by cytochrome $c$ away from complex IV and to the mitochondrial inner membrane-bound p $66^{\text {Shc }}$ to generate $\mathrm{H}_{2} \mathrm{O}_{2}$ (Giorgio et al. 2005). In the mitochondria, the ANTs are particularly sensitive to inactivation by ROS, at least in Drosophila (Yan and Sohal 1998). These various aspects of mitochondrial permeability transition now suggest an explanation for the inhibition of mitochondrial ATP hydrolysis in cancer cells following addition of uncoupler (Pedersen 1978). Because of their chronic exposure to ROS, the cancer cell mtPTPs would be hypersensitive to 
changes in $\triangle \mathrm{P}$. When uncoupler is added, the mtPTP is activated, mitochondrial ROS production increases, and the ANTs are oxidized and inactivated. With ATP-ADP exchange blocked, the ATP synthase is deprived of substrate, and ATP hydrolysis stops. However, if ATP is added before the uncoupler, the ATP would stabilize the mtPTP, blocking increased ROS production, and preserving ADP-ATP exchange and thus ATP hydrolysis.

In conclusion, the application of the mitochondrial paradigm for metabolic and degenerative diseases and aging to cancer permits us to rationalize many perplexing features of cancer biology. Moreover, it refocuses the study of cancer mitochondrial metabolism away from gross dysfunction of OXPHOS and to the interplay between the mitochondrial ROS production and the mitochondrial regulation of apoptosis. Hence, Warburg's observations can now be explained, and with this explanation, new avenues for the treatment and prevention of cancer through drugs that control mitochondrial ROS are suggested.

\section{ACKNOWLEDGMENTS}

The author thanks Ms M.T. Lott for her assistance with this manuscript. This work has been supported by National Institutes of Health grants NS21328, AG13154, NS41650, AG24373, TW01366, and HL64017 and by an Ellison Senior Scholar Award.

\section{REFERENCES}

Achanta G., Sasaki R., Feng L., Carew J.S., Lu W., Pelicano H., Keating M.J., and Huang P. 2005. Novel role of p53 in maintaining mitochondrial genetic stability through interaction with DNA Pol gamma. EMBO J. 24: 3482.

Alonso A., Martin P., Albarran C., Aquilera B., Garcia O., Guzman A., Oliva H., and Sancho M. 1997. Detection of somatic mutations in the mitochondrial DNA control region of colorectal and gastric tumors by heteroduplex and single-strand conformation analysis. Electrophoresis 18: 682.

Aoki M., Batista O., Bellacosa A., Tsichlis P., and Vogt P.K. 1998. The akt kinase: Molecular determinants of oncogenicity. Proc. Natl. Acad. Sci. 95: 14950.

Astuti D., Latif F., Dallol A., Dahia P.L., Douglas F., George E., Skoldberg F., Husebye E.S., Eng C., and Maher E.R. 2001. Gene mutations in the succinate dehydrogenase subunit SDHB cause susceptibility to familial pheochromocytoma and to familial paraganglioma. Am. J. Hum. Genet. 69: 49.

Baysal B.E., Ferrell R.E., Willett-Brozick J.E., Lawrence E.C., Myssiorek D., Bosch A., van der Mey A., Taschner P.E., Rubinstein W.S., Myers E.N., Richard C.W., Cornelisse C.J., Devilee P., and Devlin B. 2000. Mutations in SDHD, a mitochondrial complex II gene, in hereditary paraganglioma. Science 287: 848 .

Bellacosa A., Testa J.R., Staal S.P., and Tsichlis P.N. 1991. A retroviral oncogene, akt, encoding a serine-threonine kinase containing an SH2-like region. Science 254: 274.

Bianchi M.S., Bianchi N.O., and Bailliet G. 1995. Mitochondrial DNA mutations in normal and tumor tissues from breast cancer patients. Cytogenet. Cell Genet. 71: 99.

Birnbaum M.J. 2004. On the InterAktion between hexokinase and the mitochondrion. Dev. Cell 7: 781.

Bourgeron T., Rustin P., Chretien D., Birch-Machin M., Bourgeois M., Viegas-Pequignot E., Munnich A., and Rotig A. 1995. Mutation of a nuclear succinate dehydrogenase gene results in mitochondrial respiratory chain deficiency. Nat. Genet. 11: 144.

Brandon M., Baldi P., and Wallace D.C. 2006. Mitochondrial mutations in cancer. Oncogene (in press).

Brazil D.P., Yang Z.Z., and Hemmings B.A. 2004. Advances in protein kinase B signalling: AKTion on multiple fronts. Trends Biochem. Sci. 29: 233.

Brockington M., Sweeney M.G., Hammans S.R., MorganHughes J.A., and Harding A.E. 1993. A tandem duplication in the D-loop of human mitochondrial DNA is associated with deletions in mitochondrial myopathies. Nat. Genet. 4: 67.

Bustamante E. and Pedersen P.L. 1977. High aerobic glycolysis of rat hepatoma cells in culture: Role of mitochondrial hexokinase. Proc. Natl. Acad. Sci. 74: 3735.

Cai J., Wallace D.C., Zhivotovsky B., and Jones D.P. 2000. Separation of cytochrome c-dependent caspase activation from thiol-disulfide redox change in cells lacking mitochondrial DNA. Free Radic. Biol. Med. 29: 334.

Cann R.L., Stoneking M., and Wilson A.C. 1987. Mitochondrial DNA and human evolution. Nature 325: 31.

Canter J.A., Kallianpur A.R., Parl F.F., and Millikan R.C. 2005. Mitochondrial DNA G10398A polymorphism and invasive breast cancer in African-American women. Cancer Res. 65: 8028.

Chen J.Z., Gokden N., Greene G.F., Green B., and Kadlubar F.F 2003. Simultaneous generation of multiple mitochondrial DNA mutations in human prostate tumors suggests mitochondrial hyper-mutagenesis. Carcinogenesis 24: 1481.

Chen J.Z., Gokden N., Greene G.F., Mukunyadzi P., and Kadlubar F.F. 2002. Extensive somatic mitochondrial mutations in primary prostate cancer using laser capture microdissection. Cancer Res. 62: 6470.

Chinnery P.F., Samuels D.C., Elson J., and Turnbull D.M. 2002. Accumulation of mitochondrial DNA mutations in ageing, cancer, and mitochondrial disease: Is there a common mechanism? Lancet 360: 1323.

Clayton D.A., Davis R.W., and Vinograd J. 1970. Homology and structural relationships between the dimeric and monomeric circular forms of mitochondrial DNA from human leukemic leukocytes. J. Mol. Biol. 47: 137.

Copeland W.C., Wachsman J.T., Johnson F.M., and Penta J.S. 2002. Mitochondrial DNA alterations in cancer. Cancer Investig. 20: 557.

Evans A.R., Limp-Foster M., and Kelley M.R. 2000. Going APE over ref-1. Mutat. Res. 461: 83.

Fliss M.S., Usadel H., Caballero O.L., Wu L., Buta M.R., Eleff S.M., Jen J., and Sidransky D. 2000. Facile detection of mitochondrial DNA mutations in tumors and bodily fluids. Science 287: 2017.

Gatenby R.A. and Gillies R.J. 2004. Why do cancers have high aerobic glycolysis? Nat. Rev. Cancer 4: 891.

Giorgio M., Migliaccio E., Orsini F., Paolucci D., Moroni M., Contursi C., Pelliccia G., Luzi L., Minucci S., Marcaccio M., Pinton P., Rizzuto R., Bernardi P., Paolucci F., and Pelicci P.G. 2005. Electron transfer between cytochrome c and p66Shc generates reactive oxygen species that trigger mitochondrial apoptosis. Cell 122: 221.

Glaichenhaus N., Leopold P., and Cuzin F. 1986. Increased levels of mitochondrial gene expression in rat fibroblast cells immortalized or transformed by viral and cellular oncogenes. EMBO J. 5: 1261.

Goel A., Mathupala S.P., and Pedersen P.L. 2003. Glucose metabolism in cancer. Evidence that demethylation events play a role in activating type II hexokinase gene expression. $J$. Biol. Chem. 278: 15333.

Gottlob K., Majewski N., Kennedy S., Kandel E., Robey R.B., and Hay N. 2001. Inhibition of early apoptotic events by $\mathrm{Akt} / \mathrm{PKB}$ is dependent on the first committed step of glycolysis and mitochondrial hexokinase. Genes Dev. 15: 1406.

Habano W., Sugai T., Yoshida T., and Nakamura S. 1999. Mitochondrial gene mutation, but not large-scale deletion, is a feature of colorectal carcinomas with mitochondrial microsatellite instability. Int. J. Cancer 83: 625.

Harrison D.E. and Archer J.R. 1987. Genetic differences in effects of food restriction on aging in mice. J. Nutr. 117: 376.

Herrmann P.C., Gillespie J.W., Charboneau L., Bichsel V.E., Paweletz C.P., Calvert V.S., Kohn E.C., Emmert-Buck M.R., 
Liotta L.A., and Petricoin E.F., III. 2003. Mitochondrial proteome: altered cytochrome c oxidase subunit levels in prostate cancer. Proteomics 3: 1801 .

Holt I.J., Harding A.E., and Morgan-Hughes J.A. 1988. Deletions of muscle mitochondrial DNA in patients with mitochondrial myopathies. Nature 331: 717.

Holt I.J., Harding A.E., Petty R.K., and Morgan-Hughes J.A. 1990. A new mitochondrial disease associated with mitochondrial DNA heteroplasmy. Am. J. Hum. Genet. 46: 428.

Horton T.M., Petros J.A., Heddi A., Shoffner J., Kaufman A.E., Graham S.D., Jr., Gramlich T., and Wallace D.C. 1996. Novel mitochondrial DNA deletion found in a renal cell carcinoma. Genes Chromosomes Cancer 15: 95.

Ishii N., Fujii M., Hartman P.S., Tsuda M., Yasuda K., SenooMatsuda N., Yanase S., Ayusawa D., and Suzuki K. 1998. A mutation in succinate dehydrogenase cytochrome $b$ causes oxidative stress and ageing in nematodes. Nature 394: 694.

Jeronimo C., Nomoto S., Caballero O.L., Usadel H., Henrique R., Varzim G., Oliveira J., Lopes C., Fliss M.S., and Sidransky D. 2001. Mitochondrial mutations in early stage prostate cancer and bodily fluids. Oncogene 20: 5195.

Johnson M.J., Wallace D.C., Ferris S.D., Rattazzi M.C., and Cavalli-Sforza L.L. 1983. Radiation of human mitochondria DNA types analyzed by restriction endonuclease cleavage patterns. J. Mol. Evol. 19: 255.

Kelley M.R. and Parsons S.H. 2001. Redox regulation of the DNA repair function of the human AP endonuclease Ape1/ref-1. Antioxid. Redox Signal. 3: 671.

Khogali S.S., Mayosi B.M., Beattie J.M., McKenna W.J., Watkins H., and Poulton J. 2001. A common mitochondrial DNA variant associated with susceptibility to dilated cardiomyopathy in two different populations. Lancet 357: 1265.

Kirches E., Krause G., Warich-Kirches M., Weis S., Schneider T., Meyer-Puttlitz B., Mawrin C., and Dietzmann K. 2001. High frequency of mitochondrial DNA mutations in glioblastoma multiforme identified by direct sequence comparison to blood samples. Int. J. Cancer 93: 534.

Kokoszka J.E., Waymire K.G., Levy S.E., Sligh J.E., Cai J., Jones D.P., MacGregor G.R., and Wallace D.C. 2004. The $\mathrm{ADP} / \mathrm{ATP}$ translocator is not essential for the mitochondrial permeability transition pore. Nature 427: 461 .

Krieg R.C., Knuechel R., Schiffmann E., Liotta L.A., Petricoin E.F., III, and Herrmann P.C. 2004. Mitochondrial proteome: Cancer-altered metabolism associated with cytochrome c oxidase subunit level variation. Proteomics 4: 2789.

Kujoth G.C., Hiona A., Pugh T.D., Someya S., Panzer K., Wohlgemuth S.E., Hofer T., Seo A.Y., Sullivan R., Jobling W.A., Morrow J.D., Van Remmen H., Sedivy J.M., Yamasoba T., Tanokura M., Weindruch R., Leeuwenburgh C., and Prolla T.A. 2005. Mitochondrial DNA mutations, oxidative stress, and apoptosis in mammalian aging. Science 309: 481.

Kurtz A., Lueth M., Kluwe L., Zhang T., Foster R., Mautner V.F., Hartmann M., Tan D.J., Martuza R.L., Friedrich R.E., Driever P.H., and Wong L.J. 2004. Somatic mitochondrial DNA mutations in neurofibromatosis type 1-associated tumors. Mol. Cancer Res. 2: 433.

LaBiche R.A., Demars M., and Nicolson G.L. 1992. Transcripts of the mitochondrial gene ND5 are overexpressed in highly metastatic murine large cell lymphoma cells. In Vivo 6: 317 .

LaBiche R.A., Yoshida M., Gallick G.E., Irimura T., Robberson D.L., Klostergaard J., and Nicolson G.L. 1988. Gene expression and tumor cell escape from host effector mechanisms in murine large cell lymphoma. J. Cell. Biochem. 36: 393.

Lee H.C., Li S.H., Lin J.C., Wu C.C., Yeh D.C., and Wei Y.H. 2004. Somatic mutations in the D-loop and decrease in the copy number of mitochondrial DNA in human hepatocellular carcinoma. Mutat. Res. 547: 71.

Lee M.G. and Pedersen P.L. 2003. Glucose metabolism in cancer: Importance of transcription factor-DNA interactions within a short segment of the proximal region of the type II hexokinase promoter. J. Biol. Chem. 278: 41047.

Lehtonen R., Kiuru M., Vanharanta S., Sjoberg J., Aaltonen L.M., Aittomaki K., Arola J., Butzow R., Eng C., HusgafvelPursiainen K., Isola J., Jarvinen H., Koivisto P., Mecklin J.P.,
Peltomaki P., Salovaara R., Wasenius V.M., Karhu A., Launonen V., Nupponen N.N., and Aaltonen L.A. 2004. Biallelic inactivation of fumarate hydratase (FH) occurs in nonsyndromic uterine leiomyomas but is rare in other tumors. Am. J. Pathol. 164: 17.

Liu V.W., Shi H.H., Cheung A.N., Chiu P.M., Leung T.W., Nagley P., Wong L.C., and Ngan H.Y. 2001. High incidence of somatic mitochondrial DNA mutations in human ovarian carcinomas. Cancer Res. 61: 5998.

Liu V.W., Wang Y., Yang H.J., Tsang P.C., Ng T.Y., Wong L.C., Nagley P., and Ngan H.Y. 2003. Mitochondrial DNA variant $16189 \mathrm{~T}>\mathrm{C}$ is associated with susceptibility to endometrial cancer. Hum. Mutat. 22: 173.

Majewski N., Nogueira V., Robey R.B., and Hay N. 2004a. Akt inhibits apoptosis downstream of BID cleavage via a glucosedependent mechanism involving mitochondrial hexokinases. Mol. Cell. Biol. 24: 730.

Majewski N., Nogueira V., Bhaskar P., Coy P.E., Skeen J.E., Gottlob K., Chandel N.S., Thompson C.B., Robey R.B., and Hay N. 2004b. Hexokinase-mitochondria interaction mediated by Akt is required to inhibit apoptosis in the presence or absence of Bax and Bak. Mol. Cell 16: 819.

Masoro E.J. 1993. Dietary restriction and aging. J. Am. Geriatr. Soc. 41: 994.

Masoro E.J., McCarter R.J., Katz M.S., and McMahan C.A. 1992. Dietary restriction alters characteristics of glucose fuel use (erratum in J. Gerontol. [1993] 48: B73). J. Gerontol. 47: B202.

Mathupala S.P., Heese C., and Pedersen P.L. 1997a. Glucose catabolism in cancer cells. The type II hexokinase promoter contains functionally active response elements for the tumor suppressor p53. J. Biol. Chem. 272: 22776.

Mathupala S.P., Rempel A., and Pedersen P.L. 1997b. Aberrant glycolytic metabolism of cancer cells: A remarkable coordination of genetic, transcriptional, post-translational, and mutational events that lead to a critical role for type II hexokinase. J. Bioenerg. Biomembr. 29: 339.

- 2001. Glucose catabolism in cancer cells: Identification and characterization of a marked activation response of the type II hexokinase gene to hypoxic conditions. J. Biol. Chem. 276: 43407.

Mattiazzi M., Vijayvergiya C., Gajewski C.D., DeVivo D.C., Lenaz G., Wiedmann M., and Manfredi G. 2004. The mtDNA T8993G (NARP) mutation results in an impairment of oxidative phosphorylation that can be improved by antioxidants. Hum. Mol. Genet. 13: 869.

Maximo V., Soares P., Lima J., Cameselle-Teijeiro J., and Sobrinho-Simoes M. 2002. Mitochondrial DNA somatic mutations (point mutations and large deletions) and mitochondrial DNA variants in human thyroid pathology: A study with emphasis on Hurthle cell tumors. Am. J. Pathol. 160: 1857.

McCarter R.J. and Palmer J. 1992. Energy metabolism and aging: A lifelong study of Fischer 344 rats. Am. J. Physiol. 263: E448.

McCord J.M. 2000. The evolution of free radicals and oxidative stress. Am. J. Med. Genet. 108: 652.

Melov S., Ravenscroft J., Malik S., Gill M.S., Walker D.W., Clayton P.E., Wallace D.C., Malfroy B., Doctrow S.R., and Lithgow G.J. 2000. Extension of life-span with superoxide dismutase/catalase mimetics. Science 289: 1567.

Merriwether D.A., Clark A.G., Ballinger S.W., Schurr T.G., Soodyall H., Jenkins T., Sherry S.T., and Wallace D.C. 1991. The structure of human mitochondrial DNA variation. J. Mol. Evol. 33: 543.

Mishmar D., Ruiz-Pesini E.E., Golik P., Macaulay V., Clark A.G., Hosseini S., Brandon M., Easley K., Chen E., Brown M.D., Sukernik R.I., Olckers A., and Wallace D.C. 2003. Natural selection shaped regional mtDNA variation in humans. Proc. Natl. Acad. Sci. 100: 171.

Niemann S. and Muller U. 2000. Mutations in SDHC cause autosomal dominant paraganglioma, type 3. Nat. Genet. 26: 268.

Nomoto S., Yamashita K., Koshikawa K., Nakao A., and Sidransky D. 2002. Mitochondrial D-loop mutations as clonal markers in multicentric hepatocellular carcinoma and plasma. Clin. Cancer Res. 8: 481.

Parrella P., Xiao Y., Fliss M., Sanchez-Cespedes M., Mazzarelli 
P., Rinaldi M., Nicol T., Gabrielson E., Cuomo C., Cohen D., Pandit S., Spencer M., Rabitti C., Fazio V.M., and Sidransky D. 2001. Detection of mitochondrial DNA mutations in primary breast cancer and fine-needle aspirates. Cancer Res. 61: 7623.

Pedersen P.L. 1978. Tumor mitochondria and the bioenergetics of cancer cells. Prog. Exp. Tumor Res. 22: 190.

Pedersen P.L., Mathupala S., Rempel A., Geschwind J.F., and Ko Y.H. 2002. Mitochondrial bound type II hexokinase: A key player in the growth and survival of many cancers and an ideal prospect for therapeutic intervention. Biochim. Biophys. Acta 1555: 14.

Petros J.A., Baumann A.K., Ruiz-Pesini E., Amin M.B., Sun C.Q., Hall J., Lim S., Issa M.M., Flanders W.D., Hosseini S.H., Marshall F.F., and Wallace D.C. 2005. mtDNA mutations increase tumorigenicity in prostate cancer. Proc. Natl. Acad. Sci. 102: 719.

Polyak K., Li Y., Zhu H., Lengauer C., Willson J.K., Markowitz S.D., Trush M.A., Kinzler K.W., and Vogelstein B. 1998. Somatic mutations of the mitochondrial genome in human colorectal tumours. Nat. Genet. 20: 291.

Poulton J. 1998. Does a common mitochondrial DNA polymorphism underlie susceptibility to diabetes and the thrifty genotype? Trends Genet. 14: 387.

Poulton J., Brown M.S., Cooper A., Marchington D.R., and Phillips D.I. 1998. A common mitochondrial DNA variant is associated with insulin resistance in adult life. Diabetologia 41: 54.

Ruiz-Pesini E., Mishmar D., Brandon M., Procaccio V., and Wallace D.C. 2004. Effects of purifying and adaptive selection on regional variation in human mtDNA. Science 303: 223.

Schriner S.E., Linford N.J., Martin G.M., Treuting P., Ogburn C.E., Emond M., Coskun P.E., Ladiges W., Wolf N., Van Remmen H., Wallace D.C., and Rabinovitch P.S. 2005. Extension of murine life span by overexpression of catalase targeted to the mitochondria. Science 308: 1909.

Senoo-Matsuda N., Yasuda K., Tsuda M., Ohkubo T., Yoshimura S., Nakazawa H., Hartman P.S., and Ishii N. 2001. A defect in the cytochrome b large subunit in complex II causes both superoxide anion overproduction and abnormal energy metabolism in Caenorhabditis elegans. J. Biol. Chem. 276: 41553 .

Shoffner J.M., Lott M.T., Lezza A.M., Seibel P., Ballinger S.W., and Wallace D.C. 1990. Myoclonic epilepsy and ragged-red fiber disease (MERRF) is associated with a mitochondrial DNA tRNA ${ }^{\text {Lys }}$ mutation. Cell 61: 931.

Sohal R.S., Ku H.H., Agarwal S., Forster M.J., and Lal H. 1994. Oxidative damage, mitochondrial oxidant generation and antioxidant defenses during aging and in response to food restriction in the mouse. Mech. Ageing Dev. 74: 121.

Taira M., Yoshida E., Kobayashi M., Yaginuma K., and Koike K. 1983. Tumor-associated mutations of rat mitochondrial transfer RNA genes. Nucleic Acids Res. 11: 1635.

Testa J.R. and Bellacosa A. 2001. AKT plays a central role in tumorigenesis. Proc. Natl. Acad. Sci. 98: 10983.

Tong B.C., Ha P.K., Dhir K., Xing M., Westra W.H., Sidransky D., and Califano J.A. 2003. Mitochondrial DNA alterations in thyroid cancer. J. Surg. Oncol. 82: 170.

Torroni A., Stepien G., Hodge J.A., and Wallace D.C. 1990. Neoplastic transformation is associated with coordinate induction of nuclear and cytoplasmic oxidative phosphorylation genes. J. Biol. Chem. 265: 20589.

Torroni A., Lott M.T., Cabell M.F., Chen Y., Laverge L., and Wallace D.C. 1994. MtDNA and the origin of Caucasians. Identification of ancient Caucasian-specific haplogroups, one of which is prone to a recurrent somatic duplication in the Dloop region. Am. J. Hum. Genet. 55: 760.

Trifunovic A., Wredenberg A., Falkenberg M., Spelbrink J.N., Rovio A.T., Bruder C.E., Bohlooly Y.M., Gidlof S., Oldfors A., Wibom R., Tornell J., Jacobs H.T., and Larsson N.G. 2004. Premature ageing in mice expressing defective mitochondrial DNA polymerase. Nature 429: 417.

Trounce I., Neill S., and Wallace D.C. 1994. Cytoplasmic trans- fer of the mtDNA nt 8993 TG (ATP6) point mutation associated with Leigh syndrome into mtDNA-less cells demonstrates cosegregation with a decrease in state III respiration and ADP/O ratio. Proc. Natl. Acad. Sci. 91: 8334.

1995. Rescue of mitochondrial DNAs (mtDNA) from young and old human and mouse brain by fusion of synaptosomes with rho ${ }^{0}$ cultured cells. Am. J. Hum. Genet. 57: A252.

Trounce I.A., Kim Y.L., Jun A.S., and Wallace D.C. 1996. Assessment of mitochondrial oxidative phosphorylation in patient muscle biopsies, lymphoblasts, and transmitochondrial cell lines. Methods Enzymol. 264: 484.

Van Remmen H., Ikeno Y., Hamilton M., Pahlavani M., Wolf N., Thorpe S.R., Alderson N.L., Baynes J.W., Epstein C.J., Huang T.T., Nelson J., Strong R., and Richardson A. 2003. Life-long reduction in MnSOD activity results in increased DNA damage and higher incidence of cancer but does not accelerate aging. Physiol. Genomics 16: 29.

Vanharanta S., Buchta M., McWhinney S.R., Virta S.K., Peczkowska M., Morrison C.D., Lehtonen R., Januszewicz A., Jarvinen H., Juhola M., Mecklin J.P., Pukkala E., Herva R., Kiuru M., Nupponen N.N., Aaltonen L.A., Neumann H.P., and Eng C. 2004. Early-onset renal cell carcinoma as a novel extraparaganglial component of SDHB-associated heritable paraganglioma. Am. J. Hum. Genet. 74: 153.

Wallace D.C. 1992. Mitochondrial genetics: A paradigm for aging and degenerative diseases? Science 256: 628.

. 2005. A mitochondrial paradigm of metabolic and degenerative diseases, aging, and cancer: A dawn for evolutionary medicine. Annu. Rev. Genet. 39: 359.

Wallace D.C. and Lott M.T. 2002. Mitochondrial genes in degenerative diseases, cancer and aging. In Emery and Rimoin's principles and practice of medical genetics (ed. D.L. Rimoin et al.), p. 299. Churchill Livingstone, London, United Kingdom.

Wallace D.C., Brown M.D., and Lott M.T. 1999. Mitochondrial DNA variation in human evolution and disease. Gene 238: 211.

Wallace D.C., Singh G., Lott M.T., Hodge J.A., Schurr T.G., Lezza A.M., Elsas L.J., and Nikoskelainen E.K. 1988a. Mitochondrial DNA mutation associated with Leber's hereditary optic neuropathy. Science 242: 1427.

Wallace D.C., Zheng X., Lott M.T., Shoffner J.M., Hodge J.A., Kelley R.I., Epstein C.M., and Hopkins L.C. 1988b. Familial mitochondrial encephalomyopathy (MERRF): Genetic, pathophysiological, and biochemical characterization of a mitochondrial DNA disease. Cell 55: 601.

Warburg O.H. 1931. The metabolism of tumours. R.R. Smith, New York, New York.

Wu C.W., Yin P.H., Hung W.Y., Li A.F., Li S.H., Chi C.W., Wei Y.H., and Lee H.C. 2005. Mitochondrial DNA mutations and mitochondrial DNA depletion in gastric cancer. Genes Chromosomes Cancer 44: 19.

Xu Y., Krishnan A., Wan X.S., Majima H., Yeh C.C., Ludewig G., Kasarskis E.J., and St. Clair D.K. 1999. Mutations in the promoter reveal a cause for the reduced expression of the human manganese superoxide dismutase gene in cancer cells. Oncogene 18: 93.

Yan L.J. and Sohal R.S. 1998. Mitochondrial adenine nucleotide translocase is modified oxidatively during aging. Proc. Natl. Acad. Sci. 95: 12896.

Yanagihara M., Katano M., Takahashi-Sasaki N., Kimata K., Taira K., and Andoh T. 2005. Ribozymes targeting serine/threonine kinase Akt1 sensitize cells to anticancer drugs. Cancer Sci. 96: 620.

Yeh J.J., Lunetta K.L., van Orsouw N.J., Moore F.D., Jr., Mutter G.L., Vijg J., Dahia P.L., and Eng C. 2000. Somatic mitochondrial DNA (mtDNA) mutations in papillary thyroid carcinomas and differential mtDNA sequence variants in cases with thyroid tumours. Oncogene 19: 2060.

Yoneyama H., Hara T., Kato Y., Yamori T., Matsuura E.T., and Koike K. 2005. Nucleotide sequence variation is frequent in the mitochondrial DNA displacement loop region of individual human tumor cells. Mol. Cancer Res. 3: 14. 


\section{$8_{8}^{\infty} \mathrm{CSH} \&$ Cold Spring Harbor Symposia SYMPOSIA on Quantitative Biology}

\section{Mitochondria and Cancer: Warburg Addressed}

D.C. WALLACE

Cold Spring Harb Symp Quant Biol 2005 70: 363-374

Access the most recent version at doi:10.1101/sqb.2005.70.035

References This article cites 100 articles, 32 of which can be accessed free at: http://symposium.cshlp.org/content/70/363.full.htmI\#ref-list-1

\section{License}

Email Alerting Receive free email alerts when new articles cite this article - sign up in Service the box at the top right corner of the article or click here. 